\title{
INTERPERSONAL RELATIONS IN ETHICS OF SCIENCE AND TECHNOLOGIES
}

Science and technologies are defined in their foundations as tools for understanding the world. They are tools for simplifying and facilitating the life of man and society. Science and technologies are oriented towards production. The absence of humanistic aspect is leading to science not reflecting human as a person but as an object. The result of this is depersonalization. Thanks to this, manipulation is present in interpersonal relationships. Another thing that adds to this fact are new technologies which make manipulation and control easier. Concrete ethical solution to the problem of depersonalization are personalist ethics which represent the return to the human being and the respect of its dignity. Ethics of science and technologies must come from respect towards the dignity of a person. This has to reflect in the education of users of modern communication technologies. Then the ethics of science and technologies will have an actual impact on the quality of interpersonal relationships.

Keywords: power, science, technology, persons, relations

\section{Introduction}

The basic concept of our article is technology as a tool for controlling the human being. In such an environment, the possibility of interpersonal communication is lost. We will deal with the relationship between power and science, between power and reason, but also between power and modern technologies. And we will be watching the impact on interpersonal relations. As a starting point for our research, we chose a brief analysis of the relationship between the humanities and natural or rather technical sciences. In Slovak society, this relationship is in the spotlight not only of academics but also of politicians and economists. The reason for this interest is prosaic. Since the pre-1989 regime, the concept of "working intelligentsia" has been rooted in our society, which clearly defined what was expected from the intellectuals and, of course, what they were expected to do. The role of the intelligentsia was to cooperate for the common good. Unfortunately, the common good was perceived through the work in the steel industry or some other sector of the industry. Today it is perceived through turnover, profit, state budget, or the position in the ranking of international rating agencies. Sciences, regardless of its type, should be subjected to control. These agencies have defined productivity limits that determine which sciences are supported and which are liquidated.

Today, the humanities are criticized for the high numbers of students who end up without a job, for the low quality of scientific production which has a minimal global response and for overall social inefficiency. This criticism is rarely justified. However, the question remains open whether the public, negatively inclined to the humanities, reflects their importance and role in society. Therefore, a derogatory term appears referring to humanities as pseudo-sciences which do not have a real object of research and do not have a scientific method, so their results are unreliable. We will leave open the question whether they confer any social benefits or not for now, and we begin with the explanation and understanding of basic terms and content framework within which we move.

Without an emphasis on the humanistic orientation of education that would be integrated into all sciences, including the technical science, we will lose contact with the individual. Man will become an object, not only an object of research but also means of generating profits. Man will become a tool to meet the needs of another person. Mass communication controls the thinking of man and the need for it.

\footnotetext{
* ${ }^{1}$ Peter Kondrla, ${ }^{2}$ Eva Durkova

${ }^{1}$ Department of Religious Studies, Faculty of Arts, Constantine the Philosopher University, Nitra, Slovakia

${ }^{2}$ Department of General and Applied Ethics, Faculty of Arts, Constantine the Philosopher University, Nitra, Slovakia

Email: pkondrla@ukf.sk
} 


\section{Science and reason}

Science has become a symbol of modern society. After the end of the Middle Ages, a new instrument has come, aiming to conquer nature, as Francis Bacon tries to persuade us [1, p. 51]. Science ceased to listen to the authority of old sages and philosophers and relied on its own experiments to conquer nature and gain knowledge. Through knowledge, man gained power over nature, controlled it, and adapted the environment to his needs. Not that he did not behave this way before the arrival of the Modern Age, the decisive factor is the moment of power and government. Thanks to Bacon's redefinition of science's role, power becomes important, we can even say crucial when it comes to determining the role of science. To be fair, however, the way Bacon defined science is not problematic. Science is rather represented by mysterious alchemists who try to produce gold in a laboratory or discover similar miraculous technologies. But it is also represented by personalities such as Galilei, Bruno or Copernicus. During their time, scientists followed a precise code of ethics that had been controlled by the Inquisition and later by the teaching authority of the Church. Today, international organizations such as UNESCO are setting up international programs to influence the legislation, build up capacity, create an intellectual forum, raise awareness of education [2, p. 25]. If a legislative area is included, it means that a generally accepted document should be created which will define the use of specific technologies that have an ethical dimension (today this is probably included in all of them).

The subject of our article is also technology that is closely connected with the science. The concept of technology is used in the sense of a procedure, that is, a procedure of processing matter or goods in the production process. The result of using technology is a product. As long as we talk about technology, we mean a larger whole that includes not only the production process but also the means of production, resources, and the acquisition or distribution of the final products. The most appropriate combination that comes as a result of a happy compromise is the ethics of science and technology. This name is also used by UNESCO within the implementation of its international program. Science and technology represent an experimental and research base as well as applicator or technological base. The results of scientific research are applied in the practical process of production. We have here not only an aspect of cognition, thus, the aspect of experimentation and search for something new, but also an aspect of processing, creating things and lastly meddling in human life.

On the other hand, technology also acts as a tool for controlling a person. Modern technologies devour a person rendering him unfree.

\section{Reason as a ruler}

As already mentioned, the emerging science was in its early stages influenced by strong "ethical" regulations. However, the Enlightenment combined science with another attribute, that of human reason. Science has thus since been associated with reason, and only that which is scientific is reasonable [3, p. 27-28]. The role of science is not only to control nature, but it is also a means of making man use reason.

It is not science that should control the human, but it is the human himself - the human individual who uses rationality as a pretext to control unreasonable persons. On the one hand, reason fights against superstition, magic, and blind faith in the name of freedom; but on the other hand, it takes away man's freedom to fit everything into a single existing and working rational system [4, p. 19]. And here comes the fundamental question that we ask in our article. From the point of view of ethics, we hold the opinion that science is value neutral. We assume that using technology and new discoveries does not harm anyone. Only a man can harm another man when using the conveniences of science. It is a simple model of personalist ethics. Responsibility can only be found where there is freedom. If a man uses science and technology that is freely given to him, then he assumes responsibility for the consequences of his actions. The everyday use of modern technologies also impacts interpersonal relationships. At the global level, it can be positively evaluated as it allows for the creation of modern groups and communities able to cooperate on the common good. At the level of an individual, it also allows the individual to self-express through one's participation in such community. One of the realms included in the common good are interpersonal relationships. In order to create and cultivate interpersonal relationships, the use of communication and information technologies creates such opportunities that were not possible before. From a humanitarian point of view, however, it also gives rise to some problems. In what follows, we will focus on some of these problems from ethical and personalist point of view. Personalist-existentialist ethics underlines the fact that everyday use of technology is changing the perception of others in a way that an individual sees the other as something technical and technological. This enters into a relationship and contributes to its depersonalization. What are the most profound consequences of that phenomenon in our basic attitude toward the other? And, from a practical and ethical standpoint, what does it mean for our responsibility as users of current technologies?

Science and technology control not only nature but also humans. Man accepts science and technology products, but he himself becomes an object of science and technology. Not only as an object of investigation, or in medicine, but also as an object of manipulation, e.g. in marketing communication. Marketing communication penetrates into all communication channels, both private and public. This communication is not about people's 
dialogue, but about the production of artificial needs or, as Deleuze says, the desire for consumption. In communication technologies, the monologist is more like a dialogue. In a monologist stream, man is introduced to what he needs, which is important to him. Then the human individual tends to expect that in the mass society, we will all have the same needs.

Here we build on previous thoughts about rationality. Rationality is associated with usefulness. In the sense of such rationality, which seeks the simplest solutions, a person can become an object or instrument, a tool to saturate my needs. Man can also be a profit-making tool so that he can be the subject of exploitation. That is also reasonable.

Here is the place of the interpenetration of ethics, science, and technology, i.e., when we start to speak about a human person and her dignity. It is an ethical category that should be respected in science and technology, too. However, we often witness depersonalization. Ethics clearly states that a person cannot be just an instrument because, as a person, he is to be respected. Man is not an individualized existence, nor is it an insignificant part of the mass. Man is a person who exists in interpersonal relationships. The basis of these relationships is communication. Communication reveals categories of existence. It is not a space governed by the rules of rationality, but it is a space of existential communication.

\section{Technology, engineering, me and the other}

The existentialist - personalist philosopher G. Marcel explicitly formulates the aforementioned idea about the problem of depersonalization. He avoids the rigorous distinction between technology and engineering. According to him, both are inseparably related to the fact that different physical objects, systems, and processes serve us as tools, and we are using them physically or mentally to achieve the desired goal [5, p. 82], [6, p. 59-60]. We can see that we did not shift away from the concept of power, because it is a kind of power that we have over the manipulated technology. Looking at the problem as Marcel does, the fact that the other is not technology, physical object or tool that I could manipulate with the same way as technology, is not necessarily a guarantee that my relationship with him will not succumb to some of the consequences of my habitus to control. "If a person can become a slave to his habits, it is equally possible to become a prisoner of his techniques," says Marcel [5, p. 83]. It is necessary to look at "a particular relationship that tends to grow between technical processes on the one hand and human beings on the other" [5, p. 83]. However, dealing with depersonalized relationships does not mean to be satisfied with a discussion of commonly discussed phenomena (for example, the dependence between the excessive using of information technologies and decreasing amount of direct physical contact with others), but to look at the consequences in a broader context. At the same time, we should keep in mind that the use of technology is not the sole factor depersonalizing a human relationship since the depersonalization of this relationship has surely existed from the ancient times and gained various appearances independently of technological advances. Nevertheless, we feel that today it has become a factor contributing to depersonalization in an especially intensive way. We would like to show the reasons behind this stand-point by reflecting on the following analogies between technological usage and relationship with the other:

First is an analogy that we see is the analogy within, that is to say, within an organization or management of the relationship with the other. In a low-tech society, human lives, together with their pace and expectations, reflected the conformity with what we might call a rhythm capture. In the shadow of natural rhythm, human thinking has been shaped in a way that the relationship with another person was also perceived rather as an organic reality that needs time to mature. Immersed in today's artificial and technological environment, according to the cited author, the pace of our lives today is dominated more by constructivism than by natural rhythm. Natural and inner rhythms of organic realities are considered irrelevant, or we do not take them into account at all [6, p. 62-63]. We do not intend to propose the idea that human beings should organize their relationships more in the lap of mother nature. But we assume that the cited text indicates a certain type of principle, law or pattern existing in building interpersonal relationships. That is - analogously to laws governing the use of technology - that the relationship with the other also becomes the subject to constructiveness. On the other hand, we are not trying to say that human relationships do not need any organization. Contemporary technologization certainly has an unfavorable impact on the quality of the relationships, at least on the level of positive impact when it comes to efficiently organizing bigger human groups and communities, as we have already indicated above.

\section{Using technology, using the other}

Next, we wish to reflect on the analogy which we consider ethically more alarming. Reading Marcel, we are led to hold the opinion that a less artificial organization of everyday life alone would do very little to heal $m y$ depersonalized relationship with others as long as I remain looking at the other as I look at technology that I'm going to interact with. That is, when my mind is adopting a mode of thinking that is usually active when using technology. In its very nature this mode involves controlling, monitoring, repeating and perceiving technology as a problem; this is the goal which is a useful output for the one who manipulates the technology. In a sense, we are talking here about the principle of power and profit generation. For the user of technology, the technical process here is not an end in itself; it exists because of independent goals. From a certain point of view, 
that is for the human individual as a naturally practical being, this is a perfectly correct attitude. However, the situation changes radically when the technical perception begins to incorporate the kind of primacy in the general mode of our thinking [5, p. 71]. That is, for example, in the mode of our thinking towards others. Here again, we need to avoid considering this mode of technical thinking as the exclusive culprit of our conquering approach to the other. According to Marcel, we must take into account that at the current level of social organization, the person from his young age enters into a system of rivalry, a system of tests and competitions, a system of "Me and not you; Me in front of you" which "in fact, encourages man to compare himself to the other, to give himself a certain label, an assessment standard" [7, p. 73-74]. The degree of usefulness and unusefulness resulting for the individual's using contemporary technology can be assessed without major difficulties. But what happens when we look closer at the potential usefulness of "using" the other for the individual? And still, we ask this question with regard to the fact that the ultimate object of our interest is to formulate what response it conveys in relation to the responsibility that the everyday technology user should cultivate.

Within the personalist-existentialist ethics, $I$ can never be truly reduced to a content that can be precisely defined by the terms "my body, my hands, my brain." It is always a global presence" [7, p. 38]. I or He or She is always a "global and unspecified presence" [7, p. 70]. The existentialists reserve the concepts of presence and existence exclusively for a human being. Human beings are existing freedoms; everything else is only present, it just occurs. So then, according to the Marcelian logic, if I am an existing freedom, then I should also believe in a unique, i.e. not controllable existence of the other when I meet him. And this belief means that I realize or confirm his existence such as it truly is, and not only within the consequences that concern me [7, p. 78]. Marcel considers it also natural that we look at the other as "an obstacle that must be eliminated or circumvented, or as an amplifying echo that is supposed to support my natural self-complacency" [7, p. 75]. From an empirical point of view, we must state that these aspects of interpersonal relationships were also present in a society of slower technological development. In addition and with regard to historical experience, we could even consider them being efficient driving forces for the development of humans and the human society. However, it is possible to say, that in a less technologized society, to a larger extent than today, these aspects were existing next to a stronger principle of prosocial behavior and altruism. Interpersonal relationships have thus been represented in a symbiosis of two kinds of "inner settings" streaming out of myself toward the other: the other as a problem and the other as an inexpressible presence. By reflecting on the analogy between the individual's inner settings used in everyday manipulation with technologies and "inner settings" operating in the relation of one human being toward the other, we are trying to express the following concern: the other becomes more and more a problem with which a contemporary human person meets in his or her everyday contact with other human beings.

Seeing technology only as a problem, our interaction with it works accurately. The technology that we use is seen as a problem and we do not expect anything from the very interaction with it. We could say that we are interested solely in achieving the goal, which technology should help us to achieve. Such an approach has practically no impact on technology alone; in the process of manipulation, technology remains technology (unless we count as impact technological improvement possibly emerging from this manipulation). However, if this approach becomes the general habit of my thinking and influences also my perception of the other, the situation changes. According to Marcel, while technology in such manipulation remains technology, the other is in danger of me transforming him into an idea that I make up, and this idea can substitute the other, replace him in such way that I will address my actions and words to this constructed idea of him [7, p. 73]. The other is no more a problem or a mystery to me, but only one of the problems that I am daily facing with my abstract theoretical thinking. [8, p. 213], [9, p. 117], [10, p. 50].

Personalist ethics emphasizes that the other cannot be reduced to a problem. This is because if I consider myself to be an unspecified presence, then $\mathrm{He}$ or She needs to be perceived as an unspecified presence as well. But the concern that we can find in personalist ethics is much more profound. It seems that the possibility of me perceiving the other as a problem indicates a question of me perceiving myself as a problem as well. Using the words of Marcel, when I meet the other as a problem, I meet him (or her) as a case, an animated object, a set of different aspects, elements and information about him, which I could write down in a form (name, gender, occupation, age, etc.), but at the same time I reduce myself to this pen that records those elements [11, p. 9]. It seems obvious that our relationship with the other is deeply situated in the concept of dialogue. We can say that what we see in the latter example, is a kind of strange, broken metaphysical dialogue which makes me lose connection with my very true self; a kind of power which makes this dialogue broken; a power, which in my own attempt to take the other to pieces, comes back to me in its own destructive way.

\section{Conclusion or on the problem of responsibility}

When we are talking about the current user of technology and the problem of responsibility, many possible directions of concern open before us. Responsibility for the environment, responsibility for future generations, responsibility for the even organization of an economic product and so on. We could say that the theoretical problem of responsibility is needless without a practical aspect. Being responsible always means to be responsible for something or someone. Nevertheless, at the same time, responsibility is also a metaphysical problem. In personalist ethics, the problem of 
responsibility oscillates around categories such as socialization, ethical socialism, communication, friendship, admiration and so on, and all of these usually share certain common ground based on the philosophy of dialogue. But rather than dialogue in a common sense of the word, it is a metaphysical dialogue. It is a dialogue which consists in the permanent openness of me toward the other, a dialogue synonymical with some kind of interpersonal relationship between $\mathrm{Me}$ and You. From the personalists' perspective, this kind of dialogue always remains metaphysical, which means that responsibility, understood by them as rooted in that relationship, also needs to be understood as a metaphysical problem. From such point of view, it seems to be questionable whether searching for practical responsibility without some metaphysical framework is not risky. The difference between two ethicists of responsibility, Jonas and the personalist Levinas, lies in the fact that, although both agree that responsibility is based on responsibility for the idea of man, Jonas is promoting an ontological idea of existence that says "existence is supposed to be," and at the same time "how it should be "; but not that "the essence of existence is supposed to be" [12, p. 78]. In other words, our sense of responsibility should be driven by the fear that human existence would no longer exist. According to Levinas, this idea of responsibility is unthinkable without a metaphysical basis which is interpersonal. Right from the very moment the other looks at me, I am responsible for him, and I do not even have to take over the responsibility for him; this responsibility will fall to me. The proximity of the other does not mean that the other is close to me in space or as a relative, but that he is close to me from the most fundamental standpoint - I am responsible for him [13, p. 182]. It is not about a rationalized but rather experiencing responsibility.

To conclude, taking all previous reasoning and standpoints, into account we will now take responsibility as a metaphysical problem and an interpersonal relationship as was reflected above. We will try to deduce and formulate challenges which they seem to be indicating for us as everyday users of technologies.

Firstly, it seems to us that calling for responsibility in any area affected by the use of technology needs more than just something rational; it needs a sensitive cultivation of the basic relationship of Me and You. When considering how to build our awareness of shared responsibility - and to express our thought clearly enough, let us talk here about a concrete example, such as the responsibility for the environment. It cannot be only about the worry resulting from a rational knowledge of future consequences of our actions (which we today often get in various numbers and statistics), but it should be about the experienced reality leading us to reflect that the responsibility for the environment is in its deep roots the responsibility for the other as my own You. A true relationship toward the other, in a sense, is something that I can build because it is already given to me. We use technology mostly because it makes our daily life easier. But if our responsibility as technology users consists in its roots in our care for the other, then it cannot be something that we can acquire only rationally (that is by facts, statistics, and fear of known future consequences), but rather something I recognize within myself. Calling for rationality and a scientific prognosis of the future are indispensable, but it is possible that they cannot do without sensible cultivation of the basic relationship between Me and You. This is so when we consider the problem of responsibility being in its roots always a responsibility for the other, and when we accept the relationship with the other being in danger of perceiving him or her only as a problem or some tool to achieve one's goals.

Secondly, when reflecting on personalist ethics we propose that a successful call for responsibility is connected with the call for a healthy relationship toward the other. We realize that the cultivation of such relationship is a complex task requiring the use of rationality as well as engaging the inner emotional aspect. This leads us to think about the idea that a successful call to responsibility for the contemporary technology user also needs to be a cross-cutting, complex and systematic call. In other words letting ourselves express our thought with the help of a concrete example - it is not enough when the responsibility for (e.g.) our environment is highlighted during the lessons of ecology and biology, or the economic responsibility during civil education, and the responsibility for the other during the lesson of ethics or religious education and so on. It seems to us that the appeal needs to be a complex action which systematically penetrates all these areas. We would like these formulated challenges to be understood as challenges that need to become the subject of cooperation between family, school, and society; challenges that need to be understood in some manner also at the level of research and potential reforms. For example, in the mentioned case of the school environment, it would probably be useful to adjust the education system in order to cross the boundaries between technical, informational, hard sciences or arts subjects more effectively. Then there would be room for cultivating responsibility building on the facts about future consequences and, at the same time, on contemplating the responsibility through a relationship with the other. Here in our Slovak society it may be noted that the recently published document, which should represent the foundation for the future reform of our school system, outlines that the introduction of such cross-sectional subjects, considering their existence in the international space, is beneficial [14, p. 10-11] but when it comes to turning them into reality, the creator of the concrete proposals expresses some skepticism.

In the end we would like to emphasize that our goal was not to point out certain tendencies existing between the use of technology and the quality of the relationship with the other (although reflection on these tendencies remains a permanent challenge), but to express the idea that if we want the call for the cultivation of responsibility on the side of the current technology user to be successful, it needs to be a systematic appeal, engaging rational thinking and metaphysical aspects of interpersonal relationships at the same time. 


\section{kanNllkole}

Using technology in everyday life brings the call for cultivating responsibility in various directions. In this text, we wished to focus on the area of interpersonal relationships with the other because we consider it to be one of the basic platforms for an internal awareness of responsibility. To conclude we can summarize the formulated ideas in the form of several challenges. Firstly, it seems challenging not to consider maintaining the quality of $\mathrm{Me}$ and You relationship as less important than other areas affected by the use of technologies. Secondly, there is a challenge to perceive the protection of this relationship as a significant guarantor of internally experiencing and realizing the responsibility emerging from using technologies in many directions. And finally, it is also a challenge not to leave a relationship with the other without notice until the moment when undesirable consequences will themselves force us to notice it.

\section{References}

[1] HAJKO, D.: Antique Provocations. Spolok Slovenskych Spisovatelov, Bratislava, 2016.

[2] MAHRIK, T.: Kierkegaard's Metaethical Fragments. KUD Apokalipsa, Ljubljana, 2017.

[3] PETRICEK, M.: Thinking through the Image. Hermann @ synove, Praha, 2009.

[4] DELEUZE, G.: Instincts et Institutions. Textes et Documents Philosophiques. Hachette, Paris, 1955.

[5] MARCEL, G.: Man against Mass Society. Gateaway Editions, 1978.

[6] ANDERSON, T.: Technics and Atheism in Gabriel Marcel. Journal of French and Francophone Philosophy, 7(1-2), 59-68, 1995.

[7] MARCEL, G.: Me and the Other. MARCEL, G.: On the Philosophy of Hope. DVORAKOVA, V., ZILINA, M. (Trans.), Vysehrad, Praha, 1971.

[8] MARCEL, G.: Mystery of Being I. Reflection \& Mystery. Henry Regenry Company, Chicago, Illinois, 1950.

[9] MARCEL, G.: Being and Having. FARRER, K. (Tran.), Beacon Press, Boston, 1951.

[10] SWEETMAN, B.: Non - Conceptual Knowledge in Jacques Maritain and Gabriel Marcel. Journal of French and Francophone Philosophy, 7(1-2), 164-175, 1995.

[11] TREANOR, B., SWEETMAN, B.: "Gabriel (-Honore) Marcel”; 9. Disponibilite and Indisponibilite [online]. The Stanford Encyclopedia of Philosophy, ZALTA, E. N. (Ed.), Winter 2016 Edition. Available: https://plato.stanford.edu/archives/win2016/ entries/marcel/.

[12] JONAS, H.: The Principle of Responsibility. HORYNA, B., BIGL, Z. (Trans.), OIKOYMENH, Praha, 1997.

[13] LEVINAS, E.: Ethics and Infinity. DVORAKOVA, V., REJCHRT, M. (Trans.), OIKOYMNH, Praha, 1994.

[14] Ministry of Education, Science, Research and Sports of the Slovak Republic: Slovakia in Education process. National Program for Development of Education. Proposal for public discussion [online]. 1-10.12 - 1-10.14, Bratislava, 2017. Available: https://www. minedu.sk/data/files/6987_uciace_sa_slovensko.pdf [accessed 2017-08-20]. See also Ministry of Education, Science, Research and Sports of the Slovak Republic: Learning Slovakia, part 1. [online]. BURJAN, V. Available: https://www.youtube.com/ watch?v=znsBmwL-8_I\&t=24s [accessed 2017-08-20]. 